\title{
Incidental memory for the color-word association in the Stroop color-word test
}

\author{
ANDREW S. BRADLYN and HOWARD A. ROLLINS, JR. \\ Emory University, Atlanta, Georgia 30322
}

\begin{abstract}
Incidental memory for the association between color word and print color in the Stroop color-word test was examined. Subjects received either color or neutral words in various print colors or color words in black with a color patch below. Subjects named the color or the word aspect of each stimulus. For all conditions, the color-word association was held constant across trials. After naming one aspect of each stimulus, subjects were tested for their memory of the association between that aspect and the unnamed one. Subjects required more time to name the print color of color words than to perform the other event-naming tasks, and word naming was faster than color naming. Naming the print color yielded higher incidental retention of the color-word association than did naming the color patch or the word. Slowing the pace for word naming increased retention of the association. These results are discussed in relation to current models of the Stroop effect.
\end{abstract}

In many situations, the human information processor can process one message with little or no interference from other messages that are presented concurrently (e.g., Rollins \& Hendricks, 1980; Rollins \& Thibadeau, 1973; Treisman \& Davies, 1973). Since it is often relatively easy to process one message in the context of others, it is particularly interesting when situations are found in which such selection is difficult. The Stroop Color-Word Test (Stroop, 1935) is one such situation. In this task, subjects are presented color names printed in incongruent print colors. Substantial delay occurs in the naming of the color in which the color names are printed relative to the naming of the print color of neutral words or strings of Xs. In contrast, there is little or no interference caused by requiring subjects to name the color words themselves when printed in incongruent colors (cf. Dyer, 1973, for a recent review).

Furthermore, the interference observed in the Stroop test appears to occur at a relatively deep level of analysis. For instance, Klein (1964) has shown that interference occurs if subjects must name the print color for words that are color related, such as the word "sky" in red ink or "grass" in blue ink. Such a result implies that both the color of ink and the color word reach the semantic level of analysis and that interference occurs at the semantic level, possibly as subjects attempt to discriminate between the two semantic-level names available or as they organize one response to two similar semantic cues (Dyer, 1973).

Thus, the Stroop task seems to be a situation in which both the attended and unattended aspects of the stimulus are processed to a semantic or meaningful

Requests for reprints should be sent to Howard A. Rollins, Jr., Department of Psychology, Emory University, Atlanta, Georgia 30322. level of analysis. This finding suggests that memory for the unattended aspect of the stimulus word (whether the color word or print color) should be good, since items that reach the semantic level of analysis are generally well remembered whether the subject receives intentional or incidental memory instructions. In the present experiment, an attempt was made to test this hypothesis by determination of the extent to which subjects can recall the incidental aspect of the stimulus in the various Stroop conditions.

Subjects were asked to name the print color of a series of color words. Each color word was printed in an incongruent ink color. However, following Hagen (1967), repetitions of each color name always occurred in the same print color. After naming the print color for each stimulus several times in random order, subjects were shown color patches matching each print color (the attended aspect) and asked what color word (unattended aspect) in the preceding naming task was printed in that color. A similar procedure was followed for groups receiving the reverse Stroop test (naming the color word and memory test on print color) and for control groups receiving neutral words printed in various colors. If the unattended aspect of the stimulus is processed to the semantic level of analysis, one would expect above chance retention of this information across all conditions.

However, memory for the unattended aspect of the stimulus might be higher in the condition in which print color is the attended aspect simply because more time is required to process print color (the Stroop effect) and, therefore, more time is potentially available to store the color word. In order to determine whether time per se is the primary factor controlling retention, another group of subjects were run in the word-naming condition with the pace for naming the words matched 
to the average time for naming print color in the standard Stroop condition.

Finally, Flowers and Stoup (1977) have suggested that the interfering effects with Stroop-type material may depend upon the degree to which the subject can narrow the spatial span of attention in such a way as to perceive one aspect of the stimulus and ignore other aspects. However, Flowers and Stoup found that when subjects were asked to name the spatially separated color, color words continued to produce some interference, even with considerable practice. These findings led to one additional manipulation in the present study. Stroop stimuli were constructed in which the color word and the print color were spatially separated. Color words were printed in black with a small color patch immediately beneath the word. If the present results are consistent with Flowers and Stoup, then standard interference effects should occur with the stimulus aspects spatially separated. In addition, one would anticipate that retention of the relationship between the two aspects would also be substantial. On the other hand, if the separation of the two aspects results in selective focusing of attention to one spatial location, then both the interference effect and memory for the association should be reduced.

\section{METHOD}

\section{Subjects and Design}

Ninety undergraduates recruited from introductory psychology courses at Emory University volunteered to participate in the present experiment. Ten subjects were randomly assigned to each of the nine conditions generated by factorially combining three stimulus conditions with three response conditions. In the first stimulus condition, subjects were presented color words printed in incongruent colors; in the second condition, subjects were presented neutral words in the same print colors as above. In the third stimulus condition, color words were printed in black with a small incongruent color patch corresponding to the print colors in the other conditions placed just beneath each word. One-third of the subjects in each stimulus condition named the print color (or patch); two-thirds named the word. One half of the subjects naming the word proceeded at their own pace; the other half proceeded at a slow pace set by the experimenter to equal the average pace of the group naming print color. The latter condition permitted a comparison of the memory performance of the various stimulus conditions with processing time held constant.

Subjects were not aware of the fact that each color or neutral word was always paired with the same print color (patch) across exposures to each word. Following the naming task, all subjects were tested for their incidental retention of this association. All subjects were presented the previously named aspect of each word-color combination and asked to name the irrelevant and previously unnamed aspect of that combination.

\section{Stimulus Materials}

Three sets of stimulus materials were constructed for each stimulus condition. Each set of materials consisted of four $21.6 \times 29.2 \mathrm{~cm}$ sheets of heavy bond, white paper. Each sheet of paper contained five rows of stimuli, with seven word-color combinations per row. For color words in incongruent print, the stimuli on each row consisted of seven color words hand printed in one of seven incongruent colors. Each color word always appeared in the same print color, as follows: BLUE in orange print, YELLOW in purple print, RED in blue print, ORANGE in green print, PURPLE in red print, GREEN in brown print, and BROWN in pink print. All seven word-color combinations appeared in random order on each of the 20 rows, with the restriction that across adjacent rows, a stimulus never occur in the same column or an immediately adjacent column.

For the condition with neutral words, seven words neutral with respect to color replaced the color words. Again, the pairing of a word and print color remained constant across the 20 rows, as follows: HOUSE in red print, DESK in blue print, DOG in green print, CAR in orange print, DOOR in brown print, TABLE in purple print, and BOOK in pink print. The order of stimuli within a row was random, with the same restrictions as above.

For conditions in which word and color were separate, the same seven color words used above were printed in black ink. Immediately beneath each color word was a $1.75 \times 1.0 \mathrm{~cm}$ rectangular color patch. The color patches corresponded to the colors used above and were paired with the same incongruent color word as for the standard Stroop condition. Stimuli were ordered within each row in a fashion similar to the first two conditions.

For the incidental test of memory for the word-color combination, three sets of stimulus materials were constructed using white unlined index cards. For the first set of materials, a $1.75 \times 1.0 \mathrm{~cm}$ rectangular color patch was centered on the index card. Seven such cards were constructed, one for each print color used on the Stroop cards described above. The seven cards in the second set each contained a single color word printed in black. The seven cards in the third set each contained one of the neutral words centered and printed in black.

\section{Procedure}

Each subject was tested individually in a small room containing a table and two chairs. A small easel was placed on the table so that the various stimulus cards could be placed in a good viewing position for the subject.

Subjects were informed that the experiment was about the interference effects that color has on attention, that they would be presented words and colors, and that their task was to report aloud the print color or word for each stimulus, depending on condition. Subjects were told that this task was a test of speed and that they should go as quickly as possible but, since it was also a test of accuracy, make as few mistakes as possible. Subjects were instructed to continue to the next stimulus if they made a mistake. The experimenter presented the four sheets containing the Stroop stimuli one at a time and recorded the time from the subject's response to the first stimulus on the sheet to the response to the last stimulus on that sheet.

One-third of the subjects were instructed to report the color of the print (or color patch) as quickly as possible. Another one-third of the subjects were required to report the words as quickly as possible. The final one-third of the subjects were paced by the experimenter. Each subject in this condition was told to name each word as the experimenter pointed to it. The purpose of the pacing was to slow down the reading of the color words to match the time required to name print color in the Stroop condition. Consequently, the experimenter slowed the pace for these subjects so that the time per stimulus card approximated the pace for the subjects naming print color in the standard Stroop condition (approximately $30 \mathrm{sec} / \mathrm{card}$ ). Subjects in the paced condition were run after the other group.

At the time of the incidental memory test, subjects were told that in the preceding task the word-color combination was constant across the rows of stimuli and that the experimenter wished to determine whether the subject could remember the relationship between the two aspects. Subjects were presented one at a time with the appropriate set of seven test cards. The cards for each condition gave the subject the single aspect of the word-color combination that the subject had named in the 
preceding task. The subject was asked to name the incidental aspect of the combination. Subjects were told to guess if they were not certain and were given all the time they wished to make a choice. However, a response was required to each stimulus.

\section{RESULTS}

The four times, one for each response card, were averaged to yield a single response time for each subject. The mean response times for the three stimulus conditions and within each condition for the two naming tasks are presented in Table 1. It is obvious in Table 1 that the Stroop phenomena are replicated in the present experiment. Subjects required on average approximately $7 \mathrm{sec}$ additional time to respond to the print color of color words than of neutral words. Furthermore, response times were much faster for naming words than for naming colors, and stimulus condition did not appear to affect word-naming times.

A 2 (stimulus condition) by 2 (response condition) factorial analysis of variance was performed on these response times. There were significant main effects of both stimulus condition $[\mathrm{F}(2,54)=3.65, \mathrm{p}<.05$, $\mathrm{MSe}=230.13]$ and response condition $[\mathrm{F}(1,54)=$ $218.01, \mathrm{p}<.05]$. In addition, the interaction of these two variables was significant $[F(2,54)=7.79, p<.05]$. An analysis of the simple main effects of stimulus condition for subjects required to name the color of the stimulus was significant $[F(1,54)=10.65, p<.05]$. However, for word naming, there was no effect of stimulus condition $[F(1,54)=.79]$. Thus, these analyses confirm the observations described above.

Incidental retention of the association between the named aspect of the stimulus and the unnamed aspect of the stimulus are also presented in Table 1 . The mean proportions of the seven associations recalled for each of the nine conditions are shown. The response condition in which subjects were paced by the experimenter is added here. A 3 (stimulus condition) by 3 (response condition) analysis of variance was performed on these recall data. There were significant main effects of stimulus condition $[\mathrm{F}(2,81)=9.76, \mathrm{p}<.05, \mathrm{MSe}=.035]$ and response condition $[\mathrm{F}(2,81)=9.49, \mathrm{p}<.05]$. In addition, the interaction of these two variables was significant $[F(4,81)=2.98, p<.05]$. A series of analyses of simple main effects and subsequent Newman-Keuls post hoc analysis of pairs of means were computed to isolate the effects within this interaction. In addition, each proportion was compared statistically with chance performance by $t$ test. For eight of the nine conditions, one of seven common color names was the appropriate response set, and so the chance level selected was $1 / 7$ (.141). Proportions significantly higher than chance are marked by asterisk in Table 1 .

Several results are evident in Table 1 and significant by one of the above analyses. First, memory for the incidental aspect of the stimulus was uniformly at or below chance and low relative to the other groups for all groups in which color and word were separated. Clearly, the attended aspect of the stimulus in these conditions can be named quickly without interference from the unattended aspect, and memory for the unattended aspect does not occur. However, for the standard Stroop stimuli in which words are printed in various colors, recall is reasonably good, with above chance performance in five of six conditions.

When subjects must attend to and name the print color, accompanying color words are remembered better than are the neutral words. However, this finding may be a result of the lower guessing rate for neutral words. On the other hand, when subjects attend to and name the word that is presented, memory for the associated print color of color words is below chance and significantly below the memory for print color of neutral words, as well as below the memory for color words when attention is given to print color. In other words, incidental memory for the print color of color words is suppressed relative to memory for print color with neutral words. One explanation for the lower memory performance in the conditions in which subjects must name words and remember print colors is that the time to name the words is much faster than the time to name print colors. This reduction in time might reduce the time available for encoding and storing the color of print. In the paced condition, an attempt was made to slow down reading of the words in order to determine if this additional time per se would enable more printcolor encoding to occur. Clearly, the additional time did improve memory for print color in both the neutral-

Table 1

Mean Time to Respond and Mean Proportion Recalled as a Function of Stimulus Condition and Response Condition

\begin{tabular}{|c|c|c|c|c|c|c|c|c|c|c|}
\hline \multirow[b]{4}{*}{ Stimulus Condition } & \multicolumn{10}{|c|}{ Response Condition } \\
\hline & \multicolumn{4}{|c|}{ Time to Respond } & \multicolumn{6}{|c|}{ Proportion Recalled } \\
\hline & \multicolumn{2}{|c|}{$\begin{array}{l}\text { Color Named } \\
\text { Word Recalled }\end{array}$} & \multicolumn{2}{|c|}{$\begin{array}{l}\text { Word Named } \\
\text { Color Recalled }\end{array}$} & \multicolumn{2}{|c|}{$\begin{array}{l}\text { Color Named } \\
\text { Word Recalled }\end{array}$} & \multicolumn{2}{|c|}{$\begin{array}{l}\text { Word Named } \\
\text { Color Recalled }\end{array}$} & \multicolumn{2}{|c|}{$\begin{array}{c}\text { Word } \\
\text { Named** }\end{array}$} \\
\hline & Mean & SD & Mean & SD & Mean & SD & Mean & SD & Mean & $\mathrm{SD}$ \\
\hline Color Words/Incongruent Print Color & 32.88 & 5.16 & 13.12 & 2.70 & $.50 *$ & .21 & .07 & .13 & $.27 *$ & .22 \\
\hline Neutral Words/Print Color & 25.75 & 2.79 & 15.12 & 3.33 & $.36^{*}$ & .11 & $.27 *$ & .24 & $.41^{*}$ & .20 \\
\hline Color Words/Incongruent Color Patch & 26.50 & 3.30 & 13.50 & 5.30 & .20 & .16 & .09 & .12 & .13 & .10 \\
\hline
\end{tabular}

*Significantly different from chance performance $(p<.05)$. **Time constant. 
word and color-word conditions. Nevertheless, incidental memory for the print color in the neutral-word condition was higher than that in the color-word condition. Furthermore, incidental memory for the print color of named color words in the paced condition continued to be lower than memory for the color words in the printcolor naming condition, even though the time through the two lists was on average the same.

\section{DISCUSSION}

The results of the present experiment warrant two conclusions. First, it is clear that while subjects attend to and name the color in which a word is printed, they are likely to process the word itself at least to a level of analysis that permits some retention of the word. In both conditions in which subjects named the print color, their memory for the associated words was significantly greater than chance and significantly higher than their memory for words when color and word were separated or for the colors when the words were named. Second, when subjects are instructed to read words and to ignore print colors, their memory for the association between word and print color is relatively less. Thus, there is an asymmetry in retention of the association between print color and word, just as there is such an asymmetry for response times.

At the most general level, the results for incidental memory are consistent with one of the widely accepted models of the Stroop phenomenon (Dyer, 1973). Subjects are said to process print color and word automatically and in parallel, with the processing of the two aspects occurring at different rates. Word processing proceeds at a more rapid pace than color processing (cf. Farisse, 1969). At any given time, then, print color is less deeply analyzed than the accompanying word. When print color is named, both print color and word are processed to the semantic level of analysis prior to response. Since in the standard Stroop condition both the word name and the print-color name are colors, it is likely that subjects simply become confused about which one to report. However, the fact that the word reaches the semantic level also implies that subjects should have good memory for this aspect of the stimulus, even though they were never told to remember it, a prediction supported by the results of the present experiment.

When subjects must name the word color, print-color processing has not proceeded as rapidly, and thus, print color does not interfere with naming color words. However, it is not so clear within the word-naming condition what to expect concerning memory for print color. Print-color processing could continue after the word is named to the semantic level, with a resulting high memory for this aspect of the stimulus. However, the present data suggest that such is not the case, since memory for print color was low. One hypothesis that would be consistent with the data from the present experiment is that print-color processing stops when each word is named. Since color processing is slower than word processing, the print-color analysis would be at a relatively low level when stopped, which should result in poor memory. However, at least in the present experiment, color words and neutral words were named at approximately the same rates. Thus, print-color processing should have ceased at the same time for both color words and neutral words, and memory for print color should be equivalent in these two conditions. In fact, memory for print color was much higher for neutral words than for color words, even when the reading rate for words was systematically slowed and equated. These data suggest that subjects do have some control over attention to print color, so that when the processing of print color might result in interference, this aspect of the stimulus can be systematically gated prior to the level at which such interference would occur.

Thus, the memory findings of the present experiment suggest that performance in the Stroop task results both from the difference in processing time for print color and words, as proposed in earlier models, and from a difference in the ability of subjects to gate words and print colors. Apparently, subjects can attenuate or gate attention to the print color of a word when such gating is beneficial. In contrast, attention to a word cannot be attenuated when subjects must name the color of print for that word. If, on the other hand, the word and color are separated and, thus, constitute different inputs to the system, then the word can be ignored when processing the color, and vice versa.

\section{REFERENCES}

DYER, F. N. The Stroop phenomenon and its use in the study of perceptual, cognitive, and response processes. Memory \& Cognition, 1973, 1, 106-120.

Farisse, P. Why is naming longer than reading? Acta Psychologica, 1969, 30, 96-103.

Flowers, J. H., \& Stoup, C. M. Selective attention between words, shapes, and colors in speeded classification and vocalization tasks. Memory \& Cognition, 1977, 5, 299-307.

HAGEN, J. W. The effect of distraction on selective attention. Child Development, 1967, 38, 685-694.

KLEIN, G. S. Semantic power measured through the interference of words with color naming. American Journal of Psychology, 1964, 77, 576-588.

Rollins, H. A., \& Hendricks, R. Processing of words presented simultaneously to eye and ear. Journal of Experimental Psychology: Human Perception and Performance, 1980, 6, 99-109.

Rollins, H. A., \& Thibadeau, R. The effects of auditory shadowing on recognition of information received visually. Memory \& Cognition, 1973, 1, 164-168.

Stroop, J. R. Studies of interference in serial verbal reactions. Journal of Experimental Psychology, 1935, 18, 643-662.

Treisman, A., \& Davies, A. Divided attention to ear and eye. In S. Kornblum (Ed.), Attention and performance IV. New York: Academic Press, 1973.

(Received for publication August 5, 1980.) 